\title{
HUBUNGAN PENGETAHUAN TENTANG ANTIDIABETIKA ORAL (ADO) DENGAN KARAKTERISTIK DEMOGRAFI, KEPATUHAN, DAN KONTROL GULA PADA PASIEN DIABETES MELLITUS TIPE 2
}

\author{
Nanda Puspita, Muliyandhayanti, Endah Cahyani \\ (Jurusan Farmasi Politeknik Kesehatan Jakarta II)
}

\begin{abstract}
The rise of diabetes mellitus (DM) prevalence requires intensive care and self-care as a key to achieve targeted glycemic control. Patients' knowledge about DM treatment is a supportive factor of achieving the target. This study was conducted to determine the relationship between patient' knowledge of oral antidiabetics (ADO) and demographic characteristics, adherence as well as clinical conditions of diabetes mellitus patients. A cross-sectional design was applied by interviewing 100 outpatients in an Integrated Diabetes Service Unit (UPDT) in Hospital $X$. The sampling technique used was consecutive sampling. Knowledge is measured by a structured questionnaire guided by the education 'Ask $5 \mathrm{O}^{\prime}$ about drugs. The results showed that the majority of diabetic patients knew the name $(74 \%)$ and efficacy (100\%) of the antidiabetic drugs being used, but they poorly understood how to use the drug (58\%) and barely knew the side effect (11\%). Bivariate analysis showed a significant relationship between demographic factors, namely age $(p=0.005)$ and education level $(p=0.025)$ and patient's medication knowledge. However, there was no significant relationship between patient's medication knowledge and medication adherence $(p=0.592)$ and $\mathrm{HbA1c}$ as glycemic control $(p=0.101)$. It can be concluded that drug knowledge in patients does not determine medication adherence and glycemic control. analysis of other factors such as patient perceptions of medication and complication conditions that may be closely related to medication adherence and sugar control is suggested.
\end{abstract}

Keywords: diabetes; knowledge; ADO; glycemic control; adherence

\begin{abstract}
Abstrak
Peningkatan prevalensi diabetes mellitus (DM) membutuhkan penanganan dan perawatan mandiri (self-care) yang intensif sebagai kunci mencapai target kontrol glikemik yang baik. Pengetahuan pasien tentang pengobatan DM adalah pendukung tercapainya target tersebut.. Penelitian bertujuan untuk menganalisis hubungan pengetahuan tentang antidiabetika oral (ADO) dengan karakteristik demografi, kepatuhan dan kondisi klinik pasien diabetes mellitus. Penelitian menerapkan desain potong lintang dengan mewawancarai 100 pasien rawat jalan di sebuah Unit Pelayanan Diabetes Terpadu (UPDT) Rumah sakit X. Teknik sampling yang dilakukan adalah consecutive sampling. Pengetahuan diukur dengan kuesioner terstruktur yang berpedoman pada edukasi 'Tanya 5 O' tentang obat. Hasil analisis deskriptif menunjukkan mayoritas pasien diabetes mengetahui nama (74\%) dan khasiat (100\%) obat antidiabetika yang digunakan, tetapi masih kurang memahami cara penggunaan (58\%) dan efek samping obat (11\%). Analisis bivariate menunjukkan adanya hubungan signifikan antara faktor demografi, yaitu usia $(p=0,005)$ dan tingkat pendidikan $(p=0,025)$ dengan pengetahuan pasien. Namun, tidak terdapat hubungan signifikan antara pengetahuan pasien dengan kepatuhan minum obat $(p=0.592)$ maupun kontrol gula $\mathrm{HbA1c}$ $(p=0.101)$. Hal ini dapat disimpulkan bahwa pengetahuan tentang obat pada pasien tidak menentukan kepatuhan minum obat dan kontrol glikemiknya. Disarankan adanya analisis faktor lain seperti persepsi pasien tentang pengobatan dan kondisi komplikasi yang mungkin berhubungan erat dengan kepatuhan minum obat dan kontrol gula.
\end{abstract}

Kata Kunci : diabetes; pengetahuan; ADO; kontrol gula; kepatuhan 


\section{PENDAHULUAN}

Diabetes mellitus (DM) merupakan salah satu penyakit degeneratif yang berkontribusi terhadap $82 \%$ kematian setelah kanker dan penyakit kardiovaskuler ${ }^{1}$. Penderita penyakit degeneratif ini mengalami peningkatan terutama di negara-negara berkembang. Di Indonesia, data riset kesehatan dasar (riskesdas) menunjukkan adanya peningkatan penderita DM sebesar 8,5\% pada tahun $2018^{2}$. Sedangkan menurut International Diabetes Federation (IDF), jumlah penyandang DM di Indonesia diprediksi akan meningkat menjadi 14,1 juta pada tahun $2035^{3}$. Peningkatan prevalensi diabetes mellitus menjadi beban kesehatan yang memerlukan penanganan berkelanjutan.

Penanganan diabetes mellitus tidak hanya melibatkan perawatan dari tenaga medis tetapi juga membutuhkan kesadaran penderita DM merawat secara mandiri penyakitnya. Hal ini dicetuskan oleh American Diabetes Association (ADA) dalam program Diabetes selfmanagement education (DSME) yang menitikberatkan pada pentingnya pengetahuan dalam membantu penderita diabetes mencapai target terapi ${ }^{4}$. Keaktifan pasien mempelajari tentang diabetes dan peningkatan pengetahuan pasien dapat mempengaruhi kontrol glikemik yang baik ${ }^{5}$. Untuk mencapai kontrol glikemik yang baik diperlukan kepatuhan pasien dalam menggunakan obat. Beberapa penelitian sebelumnya telah mengkaji hubungan pengetahuan terkait diabetes, kepatuhan, dan outcome terapi dengan hasil yang berbeda-beda. Sebagian studi menyebutkan adanya keterkaitan yang bermakna antara pengetahuan dengan perilaku patuh penderita DM dalam menggunakan obat ${ }^{6,7}$. Sedangkan, penelitian lain menyatakan tidak terdapat hubungan bermakna antara pengetahuan, kepatuhan dan outcome klinis pasien ${ }^{8}$.

Penelitian sebelumnya telah banyak menganalisis pengetahuan terkait patofisiologi penyakit diabetes mellitus dengan menggunakan kuesioner yang sudah terstandar ${ }^{7,9}$. Sementara itu, penelitian yang mengkhususkan pada pengetahuan tentang pengobatan diabetes masih terbatas. Kurangnya pengetahuan terhadap penggunaan obat DM kemungkinan dapat mengurangi kepahaman pasien akan terapi yang dijalani dan mempengaruhi kepatuhan. Mlsalnya, pasien DM yang kurang memahami bahwa obat DM harus diminum seumur hidup untuk mengontrol kadar gula dan menurunkan resiko komplikasi. Penelitian ini bertujuan untuk mendeskripsikan pengetahuan terkait obat antidiabetika oral dan mencari hubungannya dengan karakteristik pasien DM di Unit Pelayanan Diabetes Terpadu (UPDT) sebuah rumah sakit X. Hasil penelitian ini diharapkan dapat menjadi dasar bagi peningkatan pelayanan kefarmasian pada pasien diabetes mellitus. 


\section{METODE PENELITIAN}

Penelitian ini merupakan studi deskriptif analitik dengan desain potong lintang (cross sectional). Sebanyak 100 pasien diabetes mellitus rawat jalan di UPDT menjadi responden, dengan teknik consecutive sampling pada bulan Mei 2019. Kriteria inklusi sampel pada penelitian ini adalah pasien diabetes mellitus tipe 2 yang berusia di atas 18 tahun, menyetujui informed concern, dan memiliki kemampuan berkomunikasi dengan baik. Variabel yang diukur dalam penelitian adalah faktor sosiodemografi (usia, jenis kelamin, pendidikan, status pekerjaan), lama menderita diabetes, dan kadar gula (HbA1c) 3 bulan terakhir. Kemudian, variabel pengetahuan tentang pengobatan diukur pada setiap responden dengan memberi pertanyaan mengenai pengetahuan tentang pengobatan diabetes yang dijalankan, meliputi nama/kandungan obat diabetes, khasiat, cara penggunaan obat serta efek samping. Responden akan dinilai 1 apabila dapat menjawab dengan benar dan dinilai 0 apabila salah dalam menjawab atau menjawab 'tidak tahu'.

Akumulasi skor keempat pertanyaan di atas dihitung reratanya dan dikategorikan menjadi dua, yaitu; pengetahuan rendah apabila skor di bawah rerata sampel dan pengetahuan cukup apabila skor di atas rerata. Selain itu, dilakukan juga pengukuran kepatuhan minum obat dengan kuesioner Morinsky Medication Adherence Scale (MMAS-8). Hasil variabel kepatuhan dibagi menjadi dua, yaitu kategori tidak patuh bila skor MMAS-8 kurang dari 6 dan patuh bila skor 6 ke atas ${ }^{10}$. Data lainnya dikelompokkan dalam tabel distribusi frekuensi dan analisa bivariat terhadap variabelnya dilakukan dengan uji beda proporsi Chi-square dengan taraf kepercayaan 95\%. Proses analisa menggunakan aplikasi/software SPSS versi 23.

\section{HASIL PENELITIAN}

Dari 100 responden yang diteliti, lebih dari separuh proporsi (61\%) adalah perempuan, dengan persentase responden di bawah 60 tahun sedikit lebih banyak (53\%) dibanding kelompok usia di atasnya (47\%). Mayoritas responden berstatus tidak bekerja (79\%) dan telah menyelesaikan pendidikan terakhir SMA (65\%). Setelah terkumpul informasi tentang lama menderita diabetes mellitus, responden dikelompokkan menjadi dua kategori, yaitu menderita diabetes kurang (42\%) atau lebih dari lima tahun (58\%). Sebagian besar merupakan pasien yang patuh terhadap pengobatan (76\%) menurut hasil self-assesment dengan MMAS-8. Lebih dari separuh respoden tidak memiliki data kadar $\mathrm{HbA1c}$ (52 dari 100 responden), 30\% memiliki kadar yang tidak terkontrol, dan hanya 18\% yang terkontrol kadar gulanya. Data karakteristik responden selengkapnya ditunjukkan pada tabel 1. 


\begin{tabular}{|c|c|c|c|}
\hline No. & Karakteristik & Kategori & Frekuensi $(n, \%)$ \\
\hline 1. & Jenis Kelamin & $\begin{array}{l}\text { Laki-laki } \\
\text { Perempuan }\end{array}$ & $\begin{array}{l}39 \\
61 \\
\end{array}$ \\
\hline 2. & Usia & $\begin{array}{l}\text { Di bawah } 60 \text { tahun } \\
60 \text { tahun ke atas }\end{array}$ & $\begin{array}{l}53 \\
47\end{array}$ \\
\hline 3. & Tingkat Pendidikan & $\begin{array}{l}\text { Tidak tamat SMA } \\
\text { SMA ke atas }\end{array}$ & $\begin{array}{l}35 \\
65\end{array}$ \\
\hline 4. & Status Pekerjaan & $\begin{array}{l}\text { Bekerja } \\
\text { Tidak bekerja }\end{array}$ & $\begin{array}{l}21 \\
79\end{array}$ \\
\hline 5. & Lama menderita DM & $\begin{array}{l}<5 \text { tahun } \\
5 \text { tahun atau lebih }\end{array}$ & $\begin{array}{l}42 \\
58\end{array}$ \\
\hline 6. & Kepatuhan & $\begin{array}{l}\text { tidak patuh } \\
\text { patuh }\end{array}$ & $\begin{array}{l}24 \\
76\end{array}$ \\
\hline 7. & $\begin{array}{l}\text { Kontrol Gula } \\
(\mathrm{HbA} 1 \mathrm{c})\end{array}$ & $\begin{array}{l}\text { Tidak terkontrol }(>7.0 \%) \\
\text { Terkontrol }(\leq 7.0 \%) \\
\text { Tidak diketahui }\end{array}$ & $\begin{array}{l}30 \\
18 \\
52\end{array}$ \\
\hline
\end{tabular}

Hasil survei pengetahuan tentang pengobatan diabetes (tabel 2) menunjukkan bahwa seluruh responden mengetahui khasiat obat antidiabetika yang digunakan. Namun, pemahaman responden masih terbatas pada istilah umum, yaitu 'menurunkan gula darah', tanpa mengetahui secara spesifik kerja obat. Pada aspek kandungan/nama obat, masih terdapat $26 \%$ yang tidak mengetahui nama obat antidiabetika yang digunakan. Demikian pula pada aspek cara penggunaan obat, sebanyak $42 \%$ responden tidak mengetahuinya dengan tepat. Hal ini terutama terjadi pada responden usia di atas 60 tahun yang meminum obat dengan pendampingan anggota keluarga. Aspek keempat yaitu pengetahuan tentang efek samping, mayoritas responden tidak mengetahui tanda dari efek samping obat (89\%)

\section{Tabel 2. Gambaran Pengetahuan tentang Antidiabetika Oral pada pasien DM}

\begin{tabular}{clcc}
\hline No. & \multicolumn{1}{c}{$\begin{array}{c}\text { Komponen Pengetahuan } \\
\text { tentang obat }\end{array}$} & $\begin{array}{c}\text { Tahu } \\
(\mathrm{n}, \%)\end{array}$ & $\begin{array}{c}\text { Tidak Tahu } \\
(\mathrm{n}, \%)\end{array}$ \\
\hline 1. & $\begin{array}{l}\text { Nama/kandungan obat } \\
\text { diabetes }\end{array}$ & 74 & 26 \\
\hline 2. & Khasiat obat diabetes & 100 & 0 \\
\hline 3. & $\begin{array}{l}\text { Cara penggunaan obat } \\
\text { diabetes }\end{array}$ & 58 & 42 \\
\hline 4. & Efek samping obat diabetes & 11 & 89 \\
\hline
\end{tabular}

Masing-masing responden memperoleh skor akumulasi pengetahuan yang kemudian ditentukan mediannya (data tidak terdistribusi normal). Dalam penelitian ini diketahui median skor $=3$, sehingga kategori pengetahuan terbagi menjadi 2 yaitu; pengetahuan rendah (skor $<3$ ) dan pengetahuan cukup (skor $\geq 3$ ). Data pengetahuan responden yang tergambar dalam tabel 3 menunjukkan bahwa lebih dari dua pertiga responden memiliki pengetahuan yang cukup. 


\section{Tabel 3. Distribusi Pengetahuan tentang Antidiabetika Oral pada pasien DM}

\begin{tabular}{llc}
\hline Variabel & Kategori & Jumlah $(\mathrm{n}, \%)$ \\
\hline Pengetahuan tentang & Pengetahuan rendah $(<3)$ & 29 \\
\cline { 2 - 3 } pengobatan ADO & Pengetahuan cukup $(\geq 3)$ & 71 \\
\hline
\end{tabular}

Responden yang sudah dikategorikan berdasarkan pengetahuannya tentang pengobatan ADO kemudian dianalisis bivariat dan dihubungkan dengan karakteristik sosiodemografi dan klinik responden. Hasil analisis menunjukkan bahwa pengetahuan tentang pengobatan dengan ADO berhubungan signifikan dengan usia dan tingkat pendidikan responden $(p=0.005 ; p=0.025)$. Sementara itu, faktor lain seperti jenis kelamin, status pekerjaan, lama menderita DM, tingkat kepatuhan dan kontrol gula tidak berhubungan dengan pengetahuan tentang pengobatan ADO (tabel 4).

\section{Tabel 4. Hubungan Pengetahuan tentang Antidiabetika Oral (ADO) dengan} Karakteristik responden penderita DM tipe 2

\begin{tabular}{|c|c|c|c|c|c|}
\hline No. & Karakteristik & $\begin{array}{l}\text { Jumlah } \\
(\mathrm{N})\end{array}$ & $\begin{array}{l}\text { Pengetahuan } \\
\text { rendah }(<3) \\
(\mathrm{N})\end{array}$ & $\begin{array}{l}\text { Pengetahuan } \\
\text { cukup }(\geq 3) \\
(\mathrm{N})\end{array}$ & P-value \\
\hline \multirow[t]{3}{*}{1} & Jenis Kelamin & & & & \multirow{3}{*}{$0.445^{\mathrm{a}}$} \\
\hline & Laki-laki & 39 & 13 & 26 & \\
\hline & Perempuan & 61 & 16 & 45 & \\
\hline \multirow[t]{3}{*}{2} & Usia & & & & \multirow{3}{*}{$0.005^{\mathrm{a}}$} \\
\hline & Di bawah 60 tahun & 53 & 9 & 44 & \\
\hline & 60 tahun ke atas & 47 & 20 & 27 & \\
\hline \multirow[t]{3}{*}{3} & Tingkat Pendidikan & & & & \multirow{3}{*}{$0.025^{\mathrm{a}}$} \\
\hline & Tidak tamat SMA & 35 & 15 & 20 & \\
\hline & SMA ke atas & 65 & 14 & 51 & \\
\hline \multirow[t]{3}{*}{4} & Status Pekerjaan & & & & \multirow{3}{*}{$0.555^{\mathrm{a}}$} \\
\hline & Bekerja & 21 & 5 & 16 & \\
\hline & Tidak bekerja & 79 & 24 & 55 & \\
\hline \multirow[t]{3}{*}{5} & Lama menderita DM & & & & \multirow{3}{*}{$0.714^{\mathrm{a}}$} \\
\hline & $<5$ tahun & 42 & 13 & 29 & \\
\hline & 5 tahun atau lebih & 58 & 16 & 42 & \\
\hline \multirow[t]{3}{*}{6} & Kepatuhan (skor MMAS-8) & & & & \multirow{3}{*}{$0.592^{a}$} \\
\hline & $<6$ (tidak patuh) & 24 & 8 & 16 & \\
\hline & $\geq 6$ (patuh) & 76 & 21 & 55 & \\
\hline \multirow[t]{3}{*}{7} & Kontrol Gula (HbA1c) & & & & \multirow{3}{*}{$0.101^{b}$} \\
\hline & Tidak terkontrol (>7.0\%) & 30 & 5 & 25 & \\
\hline & Terkontrol $(\leq 7.0 \%)$ & 18 & 7 & 11 & \\
\hline
\end{tabular}

a. Continuity Correction

b. Fisher's Exact Test

\section{PEMBAHASAN}

Penanganan diabetes mellitus secara mandiri sangat penting artinya bagi outcome terapi dan kualitas hidup penderita DM. Oleh karena itu, pasien DM perlu memahami tentang penyakitnya, bagaimana pengobatan dan cara menjaga asupan gizi. Studi tentang 
pemahaman penyakit DM telah banyak dikaji menggunakan kuesioner terstandar seperti Diabetes Knowledge Questionnaire (DKQ-24) ${ }^{7,9}$. Pada studi ini lebih dikhususkan pada pengetahuan tentang terapi yaitu penggunaan antidiabetika oral (ADO). Berdasarkan hasil wawancara dengan responden penderita diabetes, dari 4 aspek pengetahuan tentang ADO (nama, khasiat, cara penggunaan \& efek samping), responden masih kurang memahami tentang nama obat, cara penggunaan dan efek samping obat. Studi serupa oleh Nita dkk menunjukkan bahwa 15 dari 38 responden (39,5\%) penderita DM menjawab salah/tidak mengetahui nama ADO yang diminum, dan dari 30 responden yang mendapat 2 jenis ADO, 15 orang diantaranya tidak mengetahui salah satu atau keduanya ${ }^{11}$. Nama obat khususnya nama generik penting untuk diketahui oleh penderita DM maupun anggota keluarga yang membantu perawatan penderita agar tidak terjadi duplikasi terapi yang merugikan. Selain itu, pada penelitian ini mayoritas responden (89\%) tidak memahami tentang efek samping obat. Hal ini sejalan dengan studi yang dilakukan oleh Nita dkk, ketika responden diwawancara, lebih dari $80 \%$ tidak mengetahui tanda-tanda hipoglikemia sebagai salah satu efek samping penggunaan $\mathrm{ADO}^{11}$. Sebagai salah satu efek samping obat antidiabetika yang perlu diwaspadai, hipoglikemia dapat terjadi saat penderita DM melewatkan jadwal makan, dalam kondisi stress, menggunakan antidiabetika oral kerja panjang atau insulin dengan dosis berlebih. Terjadinya hipoglikemia harus dihindari terutama pada pasien lanjut usia ${ }^{12}$.

Hasil analisis bivariat (tabel 4) menunjukkan bahwa terdapat hubungan yang signifikan antara usia $(p=0,005)$ dengan pengetahuan tentang pengobatan diabetes. Responden berusia di bawah 60 tahun memiliki pengetahuan yang lebih baik dibanding kelompok usia 60 tahun ke atas. Hasil ini sejalan dengan studi yang menyatakan bahwa pasien berusia lanjut memiliki tingkat literasi kesehatan lebih rendah, yang dapat mempengaruhi perilakunya dalam menangani masalah kesehatan ${ }^{13}$. Disamping itu, pada kelompok usia ini terjadi penurunan fungsi kognitif yang ikut menurutkan daya serap terhadap informasi kesehatan ${ }^{13,14}$. Tingkat pendidikan responden juga memiliki hubungan bermakna dengan pengetahuan terkait pengobatan diabetes $(p=0,025)$. Sejumlah studi menunjukkan adanya keterkaitan antara tingkat pendidikan seseorang dengan kemampuannya menyerap dan mengaplikasikan pengetahuan kesehatan ${ }^{15,16}$. Responden yang telah menyelesaikan pendidikan SMA dan seterusnya memiliki skor pengetahuan lebih baik dibanding kelompok responden dengan level pendidikan di bawahnya.

Pada penelitian ini, pengetahuan tentang pengobatan diabetes juga dikaitkan dengan kepatuhan minum obat. Hasil uji Chi-square menunjukkan tidak terdapat hubungan yang bermakna $(p=0,592)$. Hal ini tampak dari proporsi responden $(21 \%)$ yang tetap patuh menggunakan obat meski memiliki pengetahuan rendah. Pengetahuan yang cukup tentang ADO pada responden juga tidak berhubungan dengan nilai HbA1c sebagai kontrol kadar gula jangka panjang penderita DM. Meskipun data HbA1c pada penelitian ini hanya 
mencakup 48 dari 100 responden, pada tabel 4 dapat dijelaskan bahwa respoden yang memiliki pengetahuan cukup lebih banyak memiliki HbA1c yang tidak terkontrol $(n=25)$ dibanding kadar terkontrol $(n=11)$. Hasil penelitian ini sejalan dengan studi oleh Larasati $\mathrm{dkk}^{8}$ yang menyatakan bahwa pengetahuan tentang DM tidak berhubungan dengan outcome klinis pasien DM $(p=0.328)$. Menurut penelitian tersebut hal ini dimungkinkan karena minimnya keikutsertaan pasien DM ke dalam kelompok PROLANIS sehingga kekurangan informasi mengenai penyakitnya, jenis terapi serta langkah perawatan diri (self-care). Studi di wilayah Pakistan terhadap 392 pasien DM tipe 2 juga menunjukkan rendahnya korelasi antara kontrol glikemik $\mathrm{HbA} 1 \mathrm{c}$ dengan pengetahuan tentang diabetes $(r=-0,036, p=0.404)$ serta kepatuhan terhadap terapi $(r=-0.071, p=0.238)^{17}$.

Adanya investigasi lebih lanjut diperlukan untuk menggali faktor-faktor yang berhubungan dengan kontrol glikemik pasien DM terutama di wilayah negara berkembang. Menurut sebuah studi, adanya satu atau lebih komorbid pada pasien DM merupakan preditor tingginya $\mathrm{HbA}_{1 \mathrm{c}^{18}}$. Selain itu menurut studi Larasati ${ }^{8}$, pola konsumsi tinggi karbohidrat di negara Indonesia dimungkinkan menjadi faktor pemicu tingginya kadar gula. Menurut Gonzalez ${ }^{19}$, selain pengetahuan (knowledge), faktor sosio-psikologis yang mempengaruhi kepatuhan terapi pada diabetes mellitus adalah rasa percaya pasien terhadap pengobatan. Sebuah studi menyatakan bahwa kepercayaan mengenai pengobatan (belief) menjadi mediator kepatuhan pasien diabetes dalam meminum obat ${ }^{20,21}$. Pasien yang secara rutin menggunakan obat yang diresepkan padanya memiliki sikap positif akan manfaat obat tersebut ${ }^{22}$. Faktor psikologis tersebut berperan penting dalam mencapai kontrol glikemik yang baik. Studi lanjutan dengan sampel lebih luas diperlukan untuk menganalisa faktor-faktor lain yang berkaitan dengan pengobatan diabetes mellitus, baik kepatuhan terapi dan kontrol gula.

\section{SIMPULAN DAN SARAN}

Pasien DM dalam penelitian ini memiliki pengetahuan yang baik tentang nama obat (74\%) dan khasiatnya (100\%), tetapi masih kurang memahami cara penggunaan obat yang tepat $(58 \%)$, dan efek samping obat tersebut (11\%). Hasil analisis dengan faktor demografi responden menunjukkan adanya hubungan yang signifikan antara pengetahuan tentang pengobatan diabetes dengan usia $(p=0.005)$ dan tingkat pendidikan $(0.025)$. Namun, pengetahuan tentang pengobatan tidak berhubungan dengan kepatuhan minum obat $(p=0.592)$ maupun kontrol gula HbA1c $(p=0.101)$. Hal ini dapat disimpulkan bahwa pengetahuan tentang obat pada pasien tidak menentukan kepatuhan minum obat dan kontrol glikemiknya. Disarankan adanya analisis faktor lain seperti persepsi pasien tentang pengobatan dan kondisi komplikasi yang mungkin berhubungan erat dengan kepatuhan minum obat dan kontrol gula. 


\section{DAFTAR PUSTAKA}

1. WHO. Global Status Report on Noncommunicable Diseases: Attaining the Nine Global Noncommunicable Diseases Targets; a Shared Responsibility.; 2014.

2. Badan Penelitian dan Pengembangan Kesehatan. Hasil Utama Riskesdas 2018.; 2018. http://www.depkes.go.id/resources/download/info-terkini/hasil-riskesdas-2018.pdf.

3. International Diabetes Federation. Diabetes Atlas. 6th ed.; 2013.

4. American Diabetes Association. Standards of medical care in diabetes - 2013. Diabetes Care. 2013;36(SUPPL.1). doi:10.2337/dc13-S011

5. Fenwick EK, Xie J, Rees G, Finger RP, Lamoureux EL. Factors associated with knowledge of diabetes in patients with type 2 diabetes using the Diabetes Knowledge Test validated with Rasch analysis. PLoS One. 2013;8(12):e80593. doi:10.1371/journal.pone.0080593

6. Nazir SUR, Hassali MA, Saleem F, Bashir S, Aljadhey H. Association Between Diabetes-related Knowledge and Medication Adherence: Results From Cross-sectional Analysis. Altern Ther Health Med. 2016;22(6):8-13. http://www.ncbi.nlm.nih.gov/pubmed/27866175. Accessed August 23, 2019.

7. Nazriati E, Pratiwi D, Restuastuti T. Pengetahuan pasien diabetes melitus tipe 2 dan hubungannya dengan kepatuhan minum obat di Puskesmas Mandau Kabupaten Bengkalis. Maj Kedokt Andalas. 2018;41(2):59-68. doi:10.25077/MKA.V41.I2.P5968.2018

8. Larasati LA, Andayani TM, Kristina SA. Hubungan Tingkat Pengetahuan terhadap Outcome Klinik Pasien Diabetes Melitus Tipe 2. J Manaj DAN PELAYANAN Farm (Journal Manag Pharm Pract. 2019;9(2). doi:10.22146/jmpf.43489

9. Yuwindry I, Wiedyaningsih C, Widodo G. PENGARUH PENGETAHUAN TERHADAP KUALITAS HIDUP DENGAN KEPATUHAN PENGGUNAAN OBAT SEBAGAI VARIABEL ANTARA PADA PASIEN DM. J Manaj dan Pelayanan Farm. 2016;6(4):249254.

10. Morisky DE, Ang A, Krousel-Wood M, Ward HJ. Predictive Validity of A Medication Adherence Measure an Outpatient Setting. https://www.ncbi.nlm.nih.gov/pmc/articles/PMC2562622/pdf/nihms52858.pdf. Accessed August 6, 2019.

11. Nita Y, Yuda A, Nugraheni G. Pengetahuan Pasien Tentang Diabetes dan Obat Antidiabetes Oral. J Farm Indones. 2012;6(1).

12. Rudijanto A, Yuwono A, Shahab A, et al. Konsensus Pengelolaan Dan Pencegahan Diabetes Mellitus Tipe 2 Di Indonesia. PB. Perkeni; 2015.

13. O'Conor R, Wolf MS, Smith SG, et al. Health Literacy, Cognitive Function, Proper Use, 
and Adherence to Inhaled Asthma Controller Medications Among Older Adults With Asthma. Chest. 2015;147(5):1307-1315. doi:10.1378/CHEST.14-0914

14. Lee Y-M, Yu HY, You M-A, Son Y-J. Impact of health literacy on medication adherence in older people with chronic diseases. Collegian. 2017;24(1):11-18. doi:10.1016/j.colegn.2015.08.003

15. Hakim DL. Hubungan Tingkat Sosial Ekonomi : Pendidikan, Penghasilan, Dan Fasilitas Dengan Pencegahan Komplikasi Kronis Pada Penyandang Diabetes Melitus Tipe 2 di Surakarta. 2018. http://eprints.ums.ac.id/66356/1/NASKAH PUBLIKASI.pdf. Accessed August 25, 2019.

16. Diaz-Quijano FA, Martínez-Vega RA, Rodriguez-Morales AJ, Rojas-Calero RA, LunaGonzález ML, Díaz-Quijano RG. Association between the level of education and knowledge, attitudes and practices regarding dengue in the Caribbean region of Colombia. BMC Public Health. 2018;18(1):143. doi:10.1186/s12889-018-5055-z

17. Nazir SUR, Hassali MA, Saleem F, Bashir S, Aljadhey H. Disease related knowledge, medication adherence and glycaemic control among patients with type 2 diabetes mellitus in Pakistan. Prim Care Diabetes. 2016;10(2):136-141. doi:10.1016/j.pcd.2015.09.004

18. Alqudah S, Jarab AS, Alefishat EA, Mayyas F, Khdour M, Pinto S. Factors Associated with Poor Hemoglobin A1c Control in Patients with Type 2 Diabetes. Curr Diabetes Rev. 2019;15(2):164-170. doi:10.2174/1573399814666180510144858

19. Gonzalez JS, Tanenbaum ML, Commissariat P V. Psychosocial factors in medication adherence and diabetes self-management: Implications for research and practice. Am Psychol. 2016;71(7):539-551. doi:10.1037/a0040388

20. Pereira M da G, Ferreira G, Machado JC, Pedras S. Beliefs about medicines as mediators in medication adherence in type 2 diabetes. Int $J$ Nurs Pract. 2019. doi:10.1111//JN.12768

21. Sweileh WM, Zyoud SH, Abu Nab'a RJ, et al. Influence of patients' disease knowledge and beliefs about medicines on medication adherence: findings from a cross-sectional survey among patients with type 2 diabetes mellitus in Palestine. BMC Public Health. 2014;14:94. doi:10.1186/1471-2458-14-94

22. Andersson Sundell K, Jönsson AK. Beliefs about medicines are strongly associated with medicine-use patterns among the general population. Int J Clin Pract. 2016;70(3):277285. doi:10.1111/ijcp.12781 